\section{FLIGHT OF THE SEA SWALLOW: A Crossreality Telematic Performance}

Roger Mills, Martin Slawig, Elke Utermöhlen, blackholefactory, Hannoversche Strasse 6938116 Braunschweig, Germany. E-mail: <roger@eartrumpet.org>,<info@blackholefactory.de>.

See $<$ www.mitpressjournals.org/toc/leon/49/1>for supplemental files associated with this issue.

Submitted: 16 February 2015

\section{Abstract}

Flight of the Sea Swallow is a cross-reality telematic performance project developed by the multimedia group blackhole-factory. Live data from distributed heat, light and movement sensors is visualised within the virtual and real-world performance spaces, with the aim of increasing tele-presence for performers and audiences. This article describes the background of the project, as well as its design and implementation over several iterative performances.

Overcoming the conceptual gap between dislocated performative interaction in telematic performance and the physical and virtual spaces in which it occurs is a recurring problematic in telematic practice and research. The Flight of the Sea Swallow project [1] attempts to address this gap by equipping networked performers with heat, light and movement sensors that visualise real-world data about their dispersed sensate environments within the virtual and located performance spaces. This provides performers and audiences with a way of further conceptualizing the distributed and experiential characteristics of dispersed telematic interaction and the locations from which it occurs. The work was performed in January and April 2014 to audiences at Kunstmuehle Studio A, Braunschweig, Germany, and online. It featured networked musicians performing from New York, USA; Sydney, Australia; and, Braunschweig, Germany.

\section{Background}

Flight of the Sea Swallow is an audiovisual telematic performance and interactive 3D virtual environment that draws on and develops a range of interdisciplinary art and technology practices, spanning the areas of networked music performance (NMP), virtual cross-reality environments, and global sound maps.

Radio Aporee is an example of an interactive global sound map with which phonographers upload field recordings to a Google Maps-supported database. Sounds are submitted with GPS coordinates and reflect the "perceptions, practices and artistic perspectives of its many contributors" [2]. Developing a perceptual sense of place from field recordings has its roots in the earlier work of the acoustic ecology movement of R. Murray Schafer [3] and, like Radio Aporee, Flight of the Sea Swallow also draws on the significance of field recordings as source material for improvised musical material.

The origins of NMP are to be found in the work of the League of Automatic Composers (1978-1983) [4], who programmed the first commercially available personal computers to trigger the electronic sounds of co-located networked machines. Recent innovation in the field has been driven by the needs of performers and technologists, and by the opportunities provided by network architectures, protocols and increasing network speeds.
Second Life (SL) is a virtual environment for NMP in which participants interact as avatars with virtual objects and places. Avatar Orchestra Metaverse [5] is an example of a group of artists and musicians that use SL as a platform for developing new musical instruments and telematic audio-visual performances.

In recent years, data from dispersed physical environments has been incorporated into online virtual environments. This has become known as cross-reality [6], and can apply to the sonification or visualisation of audio-visual data generated from real-world environments in virtual online spaces. Tidmarsh Living Observatory [7] is an example by which researchers at MIT have developed a cross-reality browser allowing users to experience the ecological processes of the observatory through the sonification of data such as fluctuations of heat with variations in pitch.

Flight of the Sea Swallow extends these practices in a virtual 3D world that incorporates data from musicians' hand and wrist movements, as well as the fluctuations in temperature and light in their physical spaces. It integrates client-server and peer-topeer (P2P) network architectures to allow musicians to play electroacoustic instruments while navigating a virtual globe of field recordings and video clips.

\section{Conceptualisation and Design}

The conceptualisation and design of the project is based on the migratory habits of the Arctic Tern flying north to south in search of light. It also draws on ideas from Bruce Chatwin's novel Anatomy of Restlessness, which meditates on the virtues of nomadic life for the stimulation of circadian rhythms and wellbeing. The performance engages with these concepts by situating the musicians as nomads in a $3 \mathrm{D}$ virtual world of colored spheres containing audio-visual recordings of global locations significant to them. As musicians traverse the virtual Sea Swallow world, their proximity to the coloured spheres triggers sound and images to which they respond in freely improvised music.

\section{Technical Framework}

The technical framework of the Sea Swallow project consists of a network of Max/MSP patches (Fig. 1) connecting the local performance space in Braunschweig, Germany, to networked nodes in New York, USA, and Sydney, Australia.

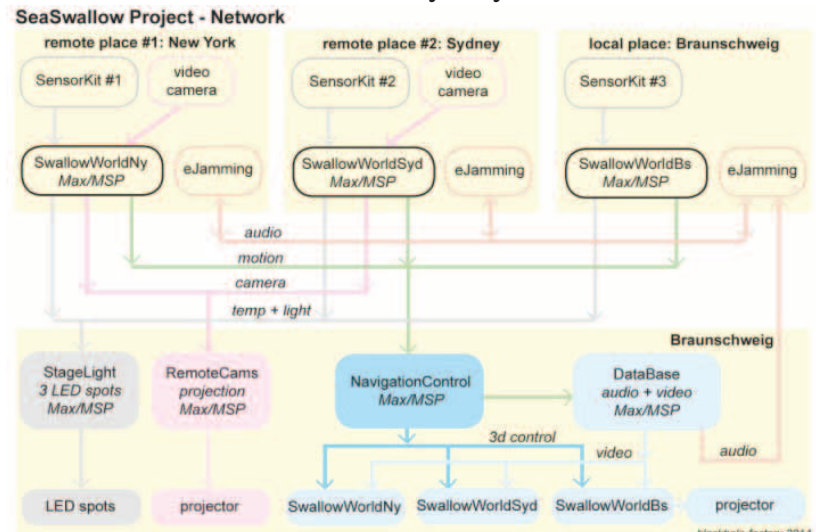

Fig. 1 Illustration of the Max/MSP Network of Patches.

The task of the Max/MSP patches is to stream and visualise sensor data from the three nodes, play back audio-visual files from the database, and display these elements as an OpenGL graphical user interface (Sea Swallow World). Networked 
performers install a sensor kit containing an Arduino UNO board [8] running a sketch (program) that reads analog sensor data and sends it to a serial object in the virtual Swallow World via a Max/MSP patch. Attached to the Arduino board are three different sensors:

- LDR (light dependent resistor) to measure gradations of light in each location.

- Temperature sensor (DS1820 Dallas 1-Wire Digital Thermometer requiring OneWire.h and DallasTemperature.h libraries on Arduino). It measures fluctuations in temperature in each location and sends the data to each performer in the virtual Sea Swallow world.

- A three-axis accelerometer (MMA7361LC) fitted to a wristband streams hand and wrist positions to the virtual hands, allowing networked performers to visually cue their movement in the virtual world.

Connecting the virtual environment of the Swallow World to the networked locations in Sydney, New York and Braunschweig is a patch that displays the motion data as $3 \mathrm{D}$ hand models in OpenGL graphics. The patch receives the motion data of all three performers and controls the virtual hands, allowing them to move and change colour for navigation (on/off, forward/backward, or stop). The patch also receives data for each remote POV in the Swallow World, calculated by the Navigation Control patch in the performance venue to syncronise all three virtual Swallow Worlds. The patch also receives the processed video stream from the database and streams it into the performance space in Braunschweig, Germany. The telematic audio interface eJamming provides the networked audio system, and realtime video streaming of dispersed performers is via mpeg-4 compressed video.

\section{Navigation Control}

Controlling performers' navigation in the virtual environment is a patch that receives the data from the three dispersed motion sensors. As soon as one performer is in navigation mode, the patch uses this motion data to control all POV parameters in the Swallow World. This is achieved through the modification of the z.glNav abstraction code from Zachary Seldess [11]. When more than one performer switches on navigation mode, the patch automatically calculates the average distance of each performer and their proximity to the virtual audio-visual spheres.

\section{Preparation and Performances}

Preparation for the performances required a number of rehearsal sessions in which performers familiarised themselves with the technology and remote navigation of the virtual environment. While the system had been trialed during construction, expanding it over multiple nodes necessitated further technological refinement. This included adapting the parameters of the accelerometers to performers' physical experiences of using them, e.g. speed, and spatial orientation, as well as modifying the algorithms used for controlling the playback of database audio-visual files based on performers' proximity to them. Likewise each performer went through a process of learning how to use the wristband and sensors to navigate the virtual Sea Swallow environment-specifically, navigating in a 'swarm,' in which dispersed performers moved their virtual hands remotely to traverse the virtual environment together. This produced some interesting results, such as the experience of hand and wrist movements being locked together, despite the geographical separation of performers. Notable, too, were the extremes of lighting states produced by evening and daytime performances, and the temperature fluctuations of the Northern and Southern performer locations.

The performances featured networked musicians - guitarist Marc Sloan (New York) and trumpeter Roger Mills (Sydney)improvising with percussion and electronics artist Martin Slawig and vocalist and electronics artist Elke Utermöhlen, who were performing to a live audience in Braunschweig, Germany. Semiscripted instructions provided a basic structure for the performances, including navigation and interaction with the virtual environment in which the performers responded in freely improvised music [12]. Audiences were also given the opportunity to try on the wristband accelerometers and interact with the virtual environment after each performance. This provided insights into the ways in which a cross-section of uninitiated participants conceptualised the performance and adapted to moving within the virtual environment. For example, people with gaming experience controlled the interface more readily than those without gaming experience.

\section{Discussion and Future Work}

Flight of the Sea Swallow is an example of a cross-reality virtual environment as a venue for telematic audiovisual performance. The project illustrates the ways in which the visualisation of realworld data from dispersed networked locations can augment performers' interaction, leading to increased tele-presence and creative engagement. Future work is required to examine the potential of using additional informational data flows (e.g. humidity, air quality), as well as the potential for sonifying this data for musical interpretation. As a first step, Flight of the Sea Swallow has provided a practice-based approach to understanding the potential use of cross-reality environments in NMP and the ways in which this can be developed further.

\section{References and Notes}

1. R. Mills, M. Slawig, M. Sloan, E. Utermöhlen, Flight of the Sea Swallow, (blackhole-factory, 2014), Telematic Performance <www.blackholefactory.com/ the-seaswallow-project/>.

2. U. Noll, Radio Aporee, <http://aporee.org/maps/>, accessed 1February 2015. 3. R.M. Schafer, The Soundscape: Our Sonic Environment and the Tuning of the World (Rochester, Vermont: Destiny Books, 1994).

4. C. Brown, J. Bischoff, History of the League,

$<$ http://crossfade.walkerart.org/brownbischoff/league_texts/league_history_f.ht $\mathrm{ml}>$, accessed 23 October 2014.

5. Avatar Orchestra Metaverse, (2007), <www.avatarorchestra.org/index.html>, accessed 25 January 2015

6. J.A. Paradiso and J.A Landay, "Guest Editor's Introduction to Cross-Reality Environments", Pervasive Computing, IEEE 8.3 (2009) pp. 14-157.

7. Tidmarsh Living Observatory, <http://tidmarsh.media.mit.edu/> accessed 3 December 2014

8. Arduino (2015), <http://arduino.cc/en/Main/arduinoBoardUno>, accessed 7 November 2014.

9. B.D. Smith, Software, (2015) <http://ben.musicsmiths.us/vipr.phtml>, accessed 16 January 2015.

10. Cycling 74, Sending matrices to a jit.net.recv object via TCP/IP

$<$ https://cycling74.com/docs/max5/refpages/jit-ref/jit.net.send.html>, accessed 15 February 2015.

11. Z. Seldess, Personal website, <www.zacharyseldess.com/software.html), accessed 8 February 2015.

12. A detailed musicological analysis of the performance is available at <http://eartrumpet.org/CIM14/cim14_117.pdf>. 
Copyright of Leonardo is the property of MIT Press and its content may not be copied or emailed to multiple sites or posted to a listserv without the copyright holder's express written permission. However, users may print, download, or email articles for individual use. 